\title{
Recognizing the Value of Threshold Concepts: Application of a Conceptual Tool to Professional Students Learning to Be Researchers
}

Kristine Alpi and Chad Hoggan, North Carolina State University, Raleigh, NC

CONTACT: Kristine Alpi, kristine_alpi@ncsu.edu Veterinary Medicine Library, North Carolina State University, CB 8401, 1060 William Moore Drive, Raleigh, NC 27607.

Citation: Kristine Alpi \& Chad Hoggan (2016): Recognizing the Value of Threshold Concepts: Application of a Conceptual Tool to Professional Students Learning to Be Researchers, The Reference Librarian, 57(2):114-130. DOI: 10.1080/02763877.2016.1121070

\begin{abstract}
Threshold concepts, as theorized by Meyer and Land, are key understandings, ways of thinking, and subjectivities that are necessary for newcomers to learn in order to participate successfully in a given field of study or practice. Every discipline and profession has threshold concepts, but often they are so integral to veterans’ participation in their field that they remain implicit until an effort is made to articulate tacit understandings into explicit learning outcomes for newcomers. Library and information science uses threshold concepts as a framework for educating all types of students in information literacy competencies expected of novice researchers. This report demonstrates how threshold concepts were articulated and implemented into a summer research scholars program for veterinary students. This article uses a typology of transformative learning outcomes as a guide to articulate threshold concepts specific for researchers in veterinary science. Through examining the context of a summer research scholars program for veterinary students, these concepts were further elucidated and considered in the implementation of information literacy learning opportunities for this program.
\end{abstract}




\section{KEYWORDS}

Information literacy; threshold concepts; transformative learning; typology; veterinary education

A growing area of research in many disciplines revolves around ways to better introduce newcomers to the key understandings, ways of thinking, and subjectivities they need to learn in order to participate successfully in the given field of study or practice; these essential conceptual and ontological norms are commonly referred to as threshold concepts (TCs) (Meyer, Land, \& Baillie, 2010). Facing and accomplishing these learning outcomes can be troublesome because they are often counterintuitive to outsiders, and thus when achieved have a transformative effect on the learners' understanding of their field (Meyer \& Land, 2003). When conducting research into TCs, an essential component is being able to effectively translate the TC into the practice of an effective educational program. This article discusses TC as an area of educational inquiry and demonstrates a structuring device to aid researchers in adapting TC research into educational practice. We use a [begin page 115] summer research scholars program for veterinary students to demonstrate how TC can be used to inform the design and delivery of the program and suggest questions for future research.

\section{Background}

While the concept of "newcomer adaptation" in socialization theory has been critically reviewed in the nursing literature as a way to understand how nursing students learn to fit with the real world of practice (Houghton, 2014; Price, 2009), few publications have discussed the use of socialization theory to shape learning activities for health professions students. Noland and Rickles (2009) interviewed pharmacy students to understand how they were socialized to the role of communication in handling and preventing medical errors and made recommendations for 
communications education based on their findings. Every discipline and profession has TCs, but often they are so integral to veterans’ participation in their field that they remain implicit until tacit understandings are articulated into explicit learning outcomes for newcomers. Even critical thinking, which most fields espouse as an essential skill, is in many ways discipline-specific (Brookfield, 2012).

Librarians involved in user education and information literacy bridge the language of the discipline, the language of information science and libraries, and the everyday language of the novice user. (See Appendix for some terms borrowed from related fields that are applicable to this article.) Librarians strive to help users understand the life cycle of information in broad domains such as the sciences, as well as more specific characteristics of information production and dissemination in those disciplines so that users can use library-provided and free resources efficiently and effectively. Teaching students to be users of information produced by others is related yet distinct from supporting students who are becoming information producers. One challenge for library educators in articulating TCs is that instructional contexts and learners often bridge multiple disciplines. The example presented in this article of information resources instruction in a summer research scholars program for veterinary students co-taught by one of the authors (K.A.) spans the disciplines of library and information science (LIS), basic science research, and veterinary medicine.

The information literacy standards for the Association of College \& Research Libraries (ACRL) provided a set of concepts and definitions on which librarians across disciplines relied for a shared vocabulary with other educators in developing information literature students. When ACRL revised those guidelines, the result was an Information Literacy Framework for Higher Education that embraced language from education and, specifically, ideas from TC theory. LIS 
has recently begun using TCs to inform the education of LIS students (Tucker, Weedman, Bruce, \& Edward, 2014) and [begin page 116] as a framework for LIS practitioners educating all types of students in information literacy competencies expected of novice researchers (ACRL, 2015; Hofer, Townsend, \& Brunetti, 2012). This borrowing of language from educational theory has been a concern to many academic librarians, particularly in terms of introducing what some view as jargon (Belin, 2015). Jargon from any field —-whether LIS, education, or veterinary medicine - creates a daunting barrier to shared understanding that can discourage participation. Although every discipline has its jargon because it is efficient and mastering jargon is part of entry to any field, librarians should resist perpetuating its use in the learning context. Appropriate use of jargon is a sign of participation but does not signify the kind of change represented by TC theory.

\section{What are threshold concepts?}

Jan (“Erik”) Meyer and Ray Land, who developed the theory of TCs, explain that every field or discipline has certain concepts, ways of knowing, and/or ways of being that are essential for newcomers in order to become an adept in that field or discipline. TCs form a barrier for newcomers who fail to assimilate them. Learning experiences whereby newcomers are able to comprehend and view the world through the lens of a particular TC are often difficult but essential. Through these TCs,

a new perspective opens up, allowing things formerly not perceived to come into view. This permits a new and previously inaccessible way of thinking about something. It represents a transformed way of understanding, or interpreting, or viewing something, without which the learner cannot progress, and result in a reformulation of the learner's frame of meaning. (Meyer et al., 2010, p. ix) 
Furthermore, a TC is likely to be transformative, irreversible, and integrative, as well as possibly being troublesome. TCs are transformative to the extent that they cause a significant shift in the learner's perception of a subject. They are irreversible because, once acquired, they are unlikely to be forgotten or unlearned without considerable effort. Also, they are integrative in that they change entire conceptions of a subject, with many implications caused by previously hidden interrelations. TCs can possibly be troublesome because they can seem counterintuitive, alien, or incoherent (Meyer \& Land, 2003; Meyer et al., 2010).

A challenge in identifying essential TCs is that they are often unique to each niche within a discipline. In the case of the summer research scholars program for veterinary students that we used for this article, we needed to consider TCs related to information literacy, health professions, and becoming a researcher. The following sections provide a brief overview of research related to TCs for these three areas. [begin page 117]

\section{Threshold concepts in information literacy}

Librarian dialogue on TCs in information literacy and instruction is passionate and evolving with librarians having both rejected and embraced TCs. Belin (2015) summarizes the controversy in a note, saying that Kevin Michael Klipfel (November 3, 2014) disapproves of TC theory as anything other than a somewhat useful way to think about deeper structures because TCs cannot be defined in a scientifically measureable way. The ACRL (2015) defined six transformative, irreversible, integrative, troublesome concepts for its information literacy framework using a Delphi study of Hofer et al. (2012) as a base. These are extensively described by ACRL:

(1) Scholarship is a conversation

(2) Research as inquiry 
(3) Authority is contextual and constructed

(4) Format as a process

(5) Searching as exploration

(6) Information has value (ACRL, 2015)

This framework includes many knowledge practices that learners should be able to perform, as well as dispositions for how those learners consider what they are doing.

\section{Threshold concepts in health professions}

There are a small number of studies discoverable in PubMed, ERIC, or ProQuest Nursing \& Allied Health Source that explicitly mention TCs for health professions students or postgraduate trainees. The few studies briefly introduced below were selected to represent a range across experience levels and disciplines from undergraduate occupational therapy students to first year veterinary students to postgraduate surgical fellows completing several years of specialized training after their medical degrees and residency programs. One of the earliest by Clouder (2005) came to identify “caring” as a TC both through a longitudinal qualitative study of the professional socialization of a cohort of occupational therapy students, and action research where students are encouraged to share critical incidents with their peers with the intention of developing skills in critical reflection.

The two early veterinary medical education examples used TCs identified by instructors from opposite ends of the knowledge spectrum — whole animal handling in the field to molecular level tests in the classroom. Cavalieri (2009) used TC as the basis for first-year veterinary student course development and resource-based learning opportunities to foster the development of pig-handling skills. From the context of teaching molecular biology concepts, Ryan and Sweeney (2007) reiterate a caution from prior work in genetics: [begin page 118] "If veterinary 
students become too immersed in the complexity of techniques, they may miss their relevance. Many textbooks illustrate landmark experiments; students often do not distinguish between the conclusion and the methods used to reach the conclusion, instead learning the material in a disconnected manner” (p. 662). Ryan and Sweeney focus on the TC of the reasoning behind the choice of the method being the key outcome, because the methods themselves are evolving. This parallels information literacy learning where the resources themselves are always changing and it is mastery of the larger concepts that remain stable that demonstrate true capacity.

Blackburn and Nestel (2014) interviewed eight pediatric surgical trainees and their thematic analysis revealed the following troublesome areas of training: breadth of knowledge and rarity of some conditions, clinical judgment expectations, technical skills, transitions between roles with increasing responsibility, relationships with trainers, and the effect of negative experiences. Negative experiences were an important catalyst inducing fundamental changes in perception that the authors felt could be characterized as a rupture of a meaning frame. Evgeniou, Tsironi, and Riley (2015) in interviews with trainers and trainees in microsurgery fellowship found that two of the cognitive skills that were both challenging and transforming for trainees were the ability to expect the unexpected and the ability to recognize complications.

\section{Threshold concepts for becoming a researcher}

Research into TCs has been conducted in a variety of disciplines and contexts. A representative example of such a study sought to articulate ways in which seasoned researchers in a variety of fields could tell when doctoral students had mastered TC related to being a researcher in their respective fields (Kiley \& Wisker, 2010). Through individual and small-group 
interviews $(n=40)$ and a written survey $(n=26)$, the researchers concluded that the following list of observable student work are indications that TCs were accomplished.

- Develop a research question from a topic ensuring a feasible and conceptual-level question.

- Develop an appropriate design and research processes for their work.

- Focus on conceptual framework, methodology, and methods

- Enter the dialogue with experts in terms of their selection and engagement with their reading in the literature review.

- Put forward an argument supported by evidence.

- Produce an abstract and a conclusions chapter that deal with concepts, not merely facts (Kiley \& Wisker, 2010, p. 411).

These observable milestones are effective guides for research advisors and educators, and they can form a basis for concrete instructional tasks. Indeed, [begin page 119] there is a large body of literature documenting TC research in various disciplines and the potential such research holds for better educational practice. (For an overview, see Meyer et al., 2010.) Whereas observable milestones are products that demonstrate when students have already accomplished TCs and can therefore be used as focal points for specific tasks that need to be learned, a complementary approach is to articulate TCs in terms of the types of change that students need to experience in order to accomplish those milestones. When designing instruction, any instructor can say, for example, that students need to be able to produce an abstract that demonstrates conceptual thinking. More effort is required for the instructor to understand the epistemological change necessary for such conceptual thinking to occur. When students struggle to cross a particular threshold, understanding the requisite transformational changes is necessary in order to 
design appropriate pedagogy. Thus, there is a translation needed between TC research and educational practice. To provide structure for this translation, we borrow a conceptual tool from transformational learning theory.

\section{Typology of transformational learning outcomes as a tool for articulating threshold}

\section{concepts}

Because of the characteristics of TCs as transformative, irreversible, and integrative, Meyer and Land argue that learning TCs is an instance of transformational learning (TL), which is a theory of learning from the discipline of adult education (Meyer et al., 2010). Dale, Pierce, and May (2010) suggest most of the participants in their UK-based study of undergraduate veterinary students underwent a perspective transformation as a result of exposure to research experiences and scientist role models. Mezirow, the seminal author of TL, defined it as a process by which

... we transform our taken-for-granted frames of reference (meaning perspectives, habits of mind, mind-sets) to make them more inclusive, discriminating, open, emotionally capable of change, and reflective so that they may generate beliefs and opinions that will prove more true or justified to guide action. . . (Its) focus is on how we learn to negotiate and act on our own purposes, values, feelings, and meanings rather than those we have uncritically assimilated from others - to gain greater control over our lives as socially responsible, clear-thinking decision makers. (Mezirow, 2000, p. 7-8)

Other authors have approached TL differently, but the various conceptions of TL still share common attributes. Namely, TL is about learning outcomes that are more pervasive in a person’s life and revolve around developing broader, more inclusive views of the world, 
becoming a more authentic person, and similar personal changes (Hoggan, 2016). These

outcomes are not necessarily—and conceptually cannot be—dictated by the norms of a particular field or discipline. Nevertheless, within the bounds of people’s professional lives, TC [begin page 120] influence how they make sense of phenomena related to their field, how they approach and solve problems, and how they interact professionally.

Thus, there is significant overlap between TC and TL. This connection makes possible a potentially valuable conceptual tool developed for TL that can be applied to TC. The Typology of Transformative Learning Outcomes (Hoggan, 2016) is a tool to help scholars articulate specific learning outcomes that have transformative effects on learners. The premise behind the typology is that learning outcomes are often better conceived as a cluster of specific changes that affect several of the following types of change and can affect any of them in multiple ways: worldview, self, epistemology (ways of knowing), ontology (ways of being), capacity, and behavior. By paying attention to the various ways people can change, scholars and practitioners are prompted to see TC that they otherwise may be blind to because of their immersion in their respective disciplines. They can better articulate what they observe or what they hope to accomplish in learning situations. Later in the article, this typology is applied as a structuring mechanism to help translate into educational practice the research surrounding TC related to helping veterinary students become scholars and information producers.

\section{Using the typology to articulate threshold concepts in the context of the Veterinary Student Summer Research Scholars Program}

Mathews (August 3, 2011) suggested that information literacy TCs should be considered by librarians at the enterprise level of learning across campus and not just be applied in "library 
instruction” (e.g., instruction we do about using library resources and developing searching skills). Librarians should ask themselves how the library can help students cross through the difficult thresholds and learn critical concepts that will enable them to succeed with their chosen major. Loertscher, Green, Lewis, Lin, and Minderhout (2014) emphasized that the primary purpose in identifying TCs for a discipline is to provide a starting point for focused curricular redesign, because an intentional approach to teaching TC is likely to result in the greatest improvement in student learning (Entwistle, 2008; Perkins, 2008). With this in mind, we chose to consider TC for veterinary science researchers in the environment of a summer veterinary research training program (the Veterinary Scholars Program) in which librarians are embedded.

The Veterinary Scholars Program aims to provide veterinary students with mentored research experiences in biomedical laboratories located within the College of Veterinary Medicine at North Carolina State University. Responsibilities of faculty mentors are very relevant to the discussion of TC as each mentor has committed to "contribute to the student's intellectual growth and development; help the student with experimental design and methodology; help the student develop experimental progress and direction; help the student [begin page 121] troubleshoot experimental problems; help develop the student's capacity for reasoning and data interpretation; and help the student think critically and objectively about their own results and ideas” (College of Veterinary Medicine, 2015). Faculty members also serve as role models and convey high ethical standards and concerns for research subjects. Librarian involvement in the course includes attendance with the students at several of the weekly seminars, leading the seminar, "Information Resources for Basic and Clinical Scientists" in the third week of the program, consulting on request with the students, and attending their public presentations of their research abstracts at the end of the program. 
The first step was to use the typology to develop a proposed list of TC for veterinary science research newcomers that could be used to shape learning activities and discussions with students, and later be further investigated through empirical research. Figure 1 shows how we aligned the TC from the three areas of literature.

Out of the diverse set of empirically-derived TC from information literacy, health professions, and those related to becoming a researcher, the first author collaborated with fellow faculty members to determine a manageable subset of TCs that were applicable to the particular context of this summer program, which we have framed here using the Typology of Transformative Learning Outcomes.

Self: Producer of knowledge

Epistemology: More discriminating (scientific method)

Epistemology: Knowledge as contextual and constructed

Ontology: Nuanced caring for animals

Ontology: Comfortable with failure

Capacity: Cognitive development to Perry’s relativism level

\section{Designing curriculum around TC}

Having framed the TC according to ways that students need to change in order to cross the various thresholds into successful participation as a veterinary researcher, curriculum can be designed to promote transformative learning in the specific domains of change (e.g., self, epistemology, ontology, and so forth). The librarian-led seminar focused on the aforementioned TCs. We did not use the terms self, epistemology, ontology, or capacity with students, but rather focused the underlying design of the program on promoting these essential learning objectives. 
Figure 1. Creation of threshold concepts using typology of transformative learning outcomes. [NB: Page 122 in published work]

\begin{tabular}{|c|c|c|c|}
\hline $\begin{array}{l}\text { Info Literacy TC } \\
\text { (ACRL) }\end{array}$ & $\begin{array}{l}\text { Health Professions } \\
\text { (Research } \\
\text { Literature) }\end{array}$ & $\begin{array}{l}\text { Veterinary Mentor } \\
\text { Objectives (CVM) }\end{array}$ & $\begin{array}{l}\text { Articulated } \\
\text { Proposed } \\
\text { Veterinary } \\
\text { Research TCs } \\
\text { (Novel) } \\
\end{array}$ \\
\hline $\begin{array}{l}\text { Scholarship is a } \\
\text { Conversation } \\
\text { Format as a Process }\end{array}$ & $\begin{array}{l}\text { Breadth of } \\
\text { knowledge and rarity } \\
\text { of some conditions }\end{array}$ & $\begin{array}{l}\text { Contribute to the student's } \\
\text { intellectual growth and } \\
\text { development }\end{array}$ & $\begin{array}{l}\text { Self: } \\
\text { Producer of } \\
\text { Knowledge }\end{array}$ \\
\hline Research as Inquiry & $\begin{array}{l}\text { Reasoning behind the } \\
\text { choice of the method }\end{array}$ & $\begin{array}{l}\text { Help the student develop } \\
\text { experimental progress and } \\
\text { direction }\end{array}$ & $\begin{array}{l}\text { Epistemology: } \\
\text { More } \\
\text { Discriminating } \\
\text { (scientific method) }\end{array}$ \\
\hline $\begin{array}{l}\text { Authority is } \\
\text { Contextual and } \\
\text { Constructed }\end{array}$ & $\begin{array}{l}\text { Reasoning behind the } \\
\text { choice of the method } \\
\text { Breadth of } \\
\text { knowledge and rarity } \\
\text { of some conditions }\end{array}$ & $\begin{array}{l}\text { Help the student think } \\
\text { critically and objectively } \\
\text { about their own results and } \\
\text { ideas }\end{array}$ & $\begin{array}{l}\text { Epistemology: } \\
\text { Knowledge as } \\
\text { Contextual and } \\
\text { Constructed }\end{array}$ \\
\hline $\begin{array}{l}\text { Information has } \\
\text { Value }\end{array}$ & $\begin{array}{l}\text { Caring } \\
\text { Clinical judgment } \\
\text { expectations }\end{array}$ & $\begin{array}{l}\text { Convey high ethical standards } \\
\text { and concerns for research } \\
\text { subjects }\end{array}$ & $\begin{array}{l}\text { Ontology: } \\
\text { Nuanced Caring for } \\
\text { Animals }\end{array}$ \\
\hline $\begin{array}{l}\text { Searching as } \\
\text { Exploration }\end{array}$ & $\begin{array}{l}\text { Ability to expect the } \\
\text { unexpected } \\
\text { Effect of negative } \\
\text { experiences; ability to } \\
\text { recognize } \\
\text { complications }\end{array}$ & $\begin{array}{l}\text { Help the student troubleshoot } \\
\text { experimental problem } \\
\text { Help develop the student's } \\
\text { capacity for reasoning and } \\
\text { data interpretation }\end{array}$ & $\begin{array}{l}\text { Ontology: } \\
\text { Comfortable with } \\
\text { Failure }\end{array}$ \\
\hline & - & $\begin{array}{l}\text { Help the student think } \\
\text { critically and objectively } \\
\text { about their own results and } \\
\text { ideas } \\
\text { Help develop the student's } \\
\text { capacity for reasoning and } \\
\text { data interpretation }\end{array}$ & $\begin{array}{l}\text { Capacity: } \\
\text { Cognitive } \\
\text { Development to } \\
\text { Perry’s Relativism } \\
\text { level }\end{array}$ \\
\hline
\end{tabular}




\section{Self: Producer of knowledge}

An important threshold that students need to cross is to identify as a producer of knowledge rather than a passive receiver. This shift in identity is necessary for students to perform several functions of a veterinary scholar. [begin page 122] When searching for extant knowledge, a producer identity allows students to critically assess published literature rather than naively accepting or generalizing claims to knowledge because a producer will be using that published literature as a base for a new creation. When designing and conducting [begin page 123] research, this identity shift is essential for students to be able to build upon research that has preceded their own, including the work of the faculty mentor.

Recognizing that a shift in identity was a necessary TC, the seminar included materials and in-class discussions designed to elicit conscious reflection by students on their place in the research lifecycle (self: producer of knowledge) and their personal strengths and growth opportunities following Moore's (2012) guidance to faculty to “capitalize on the transformative nature of disciplinary TCs and their potential to support consequential transitions” (p. 23). She suggests reflection activities where students are asked to consider changes in how they view the world and their own self-identity in light of their new knowledge and experiences. A further way that this transformation could be explored with the summer veterinary scholars is to talk with them once they are back in the throes of their veterinary medical education and see if they still feel like researchers when confronted with unsolved problems in veterinary science.

\section{Epistemology: More discriminating (scientific method) and knowledge as contextual and} constructed 
It is essential for students to become discriminating in how they read, interpret, think about, and present claims to knowledge, whether from literature or their own research. In the health professions, the universal epistemology is the scientific method. Knapp and Brower (2014) responding to the Draft 2 June 2014 version of the framework suggested that for health sciences disciplines "Research as Inquiry” (ACRL, 2015) equates to "The Scientific Method" and an understanding that research is iterative, questions are based on gaps in available information, and that as questions are addressed, new questions may arise. Students must learn to habitually think in those terms. Furthermore, this epistemological shift entails that students embrace methodological transparency. As researchers try to follow the methodologies published by others to inform their own research method decisions, they come to understand how crucial clear writing and sufficient detail are to ensuring others can use their work. This is also true within laboratories where different students or staff work on aspects of the same project, so this concept can be appreciated starting with lab notebooks and data management practices and then validated by the requirements of instructions to authors when they proceed to publications.

Another epistemological threshold over which students must pass is a shift in how they understand knowledge. They must come to understand that findings and facts are always contingent on the perspective of the researcher who conducted the study and interpreted its results. This shift alters the way the student thinks about and presents research literature. Also, with the [begin page 124] wealth of available literature, it is easy for students to bring together bits and pieces of many publications without synthesizing or reviewing the primary literature that may cut across human health, animal science, basic science, and veterinary medicine.

Developing an appreciation for the diversity of knowledge produced by the scholarly community as shown through citations across disciplines helps researchers not only understand how their 
investigation may contribute, but also how prior research has been represented in review articles or otherwise summarized.

These epistemological shifts were addressed by being explicit about knowledge and the criteria for justifying knowledge claims. One technique was to focus on the need to cite in order to support scientific integrity. What are you reporting about your knowledge of the literature when you say you have completed a "literature search"? Is that the same as completing a "literature review”? What does it mean to have searched the literature as compared to having read and synthesized it to be able to place your proposed research in the context of the available literature? When is it acceptable to rely on review articles by other scholars as opposed to doing your own review? And when it is acceptable to cite reviews rather than digging up and citing the original papers? Once you have searched the literature and formulated your question, what responsibility do you have to keep up with the topic whether through alerting strategies or regular searches to see whether the landscape has changed while you are in the process of your actual research project? Questions such as these framed the experience as activities were designed to provide structure in helping students learn to apply the appropriate epistemological lens to their work.

\section{Ontology: Nuanced caring for animals and comfortable with failure}

Animal welfare in humane experimentation under the oversight of an Institutional Animal Care and Use Committee (IACUC) is a concept with which many students struggle. Most veterinary students entered the profession because of their desire to care for animals and finding a balance between causing pain to some animals in the short term to better provide care for animals or people in the long term may require an ontological shift (nuanced care for 
animals). The required search for alternatives to animal use (replacement), and the use of the literature to examine questions of sample size (reduction) and methodology (refinement) can be challenging even to experienced researchers.

Research that does not go as planned is familiar to experienced researcher, but is a hurdle for novice researchers who may not have budgeted time for research problems. In this field, failure can be as important as successes in progressing knowledge. Students need to become resilient to and comfortable with failure, implicitly aware that not only is failure inevitable, it is not even [begin page 125] necessarily a bad thing. This ontological shift may be particularly troublesome for students in veterinary programs that tend to be highly selective, as these students likely have rarely failed at anything in their academic careers. Low success rates in the lab or field may be especially daunting for these high achieving students who have always been in control of their successes.

Promoting the two ontological shifts was particularly difficult to incorporate into the design of a summer program. In addition to a limited timeframe for this type of change, another difficulty was that the students were already past the point in their summer research work where the required IACUC search and protocol was completed by the investigators. Therefore, to address this TC in the session, the librarian inquired into whether the students had read the IACUC protocol for their program. Few had, and the librarian requested that the students discuss their protocol with their mentors.

Immersing students in iterative library research processes addressed the ontological shift of becoming comfortable with failure. Technical searching aspects of resource choice and terminology now matter more as some students report difficulty finding relevant material because of the specific nature of their research questions. Strategies that work well during their 
veterinary clinical coursework (textbooks, PubMed, and Google) fail to achieve desired results. Veterinary research for nonprimary species is a domain where not all of the relevant sources have online content that can be mined by search engines. Therefore the discussion of information as a commodity comes into play in explaining why certain content is not easily discoverable and how much libraries spend to make this content available. Vocabulary matters and students are still learning the language of their method—results vary tremendously by the terms used.

Keeping track of searching and results used to inform choices in methodology is important for reproducibility of the research as well as for preparing the content as a poster or manuscript for further dissemination. Faculty will often encourage adoption of particular databases, tools, and strategies that have been efficient for them, but will not go as far as strategizing the search terminologies that are likely to be fruitful.

\section{Capacity: Cognitive development to Perry's relativism level}

Many of the other aforementioned TCs assume that the student has achieved a certain developmental level. Using terminology from Perry's (1970) scheme of cognitive development, students need to have progressed beyond dualistic thinking (e.g., there is a correct answer, and the authorities know what it is) and multiplicity (e.g., there are many claims to knowledge, and they are all equally valid). Students must at least have reached pluralism, wherein competing knowledge claims are accepted, and they can be evaluated to determine the relative merits and value of each. [begin page 126] Presumably, students enrolled in a veterinary program will be at this level, but for those students who have yet to achieve it, their conceptions of and approach to knowledge will prohibit them from becoming adept to their intended field of study. 
The pedagogies employed were task-oriented because they were designed for a population of students who are very focused on tasks. Also, however, providing structure through tasks that were facilitated by an experienced researcher had the benefit of supporting the aforementioned form of developmental progression. Through mentor-led tasks, students were guided to recognize that multiple knowledge claims exist, that they have context-specific sources of validity, and can nevertheless be evaluated in a way appropriate to one’s discipline. Task understanding and completion fall into the Behavior category of the typology, which is a very comfortable place, but the purpose of the program is to go beyond skill development to the acquisition of the TC necessary for this particular student body. Admittedly, a summer program cannot guarantee that students will acquire all these TCs, but it can instigate and promote their development.

\section{Discussion}

In designing the component on information resources for basic and clinical veterinary scientists for this program's curriculum, the TC with which the learners engaged were not solely those reported in LIS or health professions literature independently; rather, they are specific to the transformation of becoming a researcher within the field of veterinary medicine. Transformation is an individual experience and time and experiences that lead to it may vary considerably; the summer program is a first step in creating exposure time to spark this potential for transformation. The summer program is a somewhat artificial view of the full research process. Student researchers enter in the middle of the research lifecycle as the faculty mentors are already aware of the gap in the knowledge base and have designed a project to be manageable in the 10 -week timeframe. A representative limitation of the program design is that it precludes students from negotiating with their co-investigators — who have already designed 
the IACUC protocol—-the searching components that might help to develop the TC of ontology: nuanced caring for animals. Few of the students reported having read or discussed the IACUC protocol for the project with their mentor. By the librarian seminar in the third week, three students were already in the stage of collecting data. Furthermore, not all of the students were doing projects involving biomedical data and the associated TCs; for example, one student was examining computer modeling protocols that come from other domains that document their findings in other databases. [begin page 127]

It is not possible to raise awareness of and attend to these TCs and see the effects of attending to these TCs in the course of a single educational session. For the librarian instructor author (K.A.), it was a few months after the session, having observed the students over the summer and in the reflective process of writing this article that it became clear how using the Typology organized and refined these TCs into a tighter set of more explicitly defined concepts that cover the transformation that an educator would hope to see or that the student could elucidate.

\section{Conclusion}

Librarian dialogue about TCs is growing and evolving. At a national level, ACRL has moved from labeling Threshold Concepts to Frames in Draft 2, and in the final version, to "a concept central to information literacy” (Houtman, 2015). Regardless of how they are named, our experience with thinking deeply about TC in the context of librarian-developed learning expertise for veterinary students researchers has shown us that TC are worth thinking about and discussing as a catalyst to developing a deeper understanding of the transformations possible in the learning process. Many of the practices discussed in the ACRL framework are lifelong 
learning efforts for researchers at all stages in their professional development. Library support for researchers across the research lifecycle suggests that even very experienced researchers remain challenged by the evolution of knowledge practices and can be assisted by librarians with a broad spectrum of research exposures (Vaughan et al., 2013).

The typology of transformative learning outcomes was a helpful tool for identifying TCs that students must master to participate successfully as a veterinary science researcher. We used the typology as a framework with which to combine TCs from several domains-information literacy, health professions education, and professional practices of research mentors—-to inform a seminar on information resources and practices for veterinary students training to be basic or clinical scientists. This was an exploratory effort to see whether using the typology to connect TCs from coordinating domains would have face validity in this context. Approaches in the literature to developing TC include asking students (Blackburn \& Nestel, 2014; Clouder, 2005), instructors (Hofer et al., 2012), or both students and their instructors (Evgeniou et al., 2015) through interviews or surveys and then identifying themes. This report contributes to the literature an example of how a librarian embedded with a group of learners used TC and the typology to identify stumbling blocks in becoming a veterinary researcher from not only the information literacy domain but also from broader domains. The next step is to see whether these librarian-articulated TCs resonate with [begin page 128] novice researchers-in-training or expert faculty research mentors in the domain of veterinary science research.

\section{References}

ACRL Information Literacy Competency Standards for Higher Education Task Force. (2015, January). Framework for information literacy for higher education (ACRL MW15 Doc 


\section{1). Retrieved from http://acrl.ala.org/ilstandards/wp-}

\section{content/uploads/2015/01/FrameworkMW15-Board-Docs.pdf}

Belin, I. (2015, February 25). Beyond the threshold: Conformity, resistance, and the ACRL information literacy framework for higher education. In the Library with the Leadpipe. Retrieved from http://www.inthelibrarywiththeleadpipe.org/2015/beyond-thethresholdconformity-resistance-and-the-aclr-information-literacy-framework-forhighereducation/

Blackburn, S. C., \& Nestel, D. (2014). Troublesome knowledge in pediatric surgical trainees: A qualitative study. Journal of Surgical Education, 71(5), 756-761. doi:10.1016/j.jsurg.2014.03.004

Brookfield, S. D. (2012). Teaching for critical thinking: Tools and techniques to help students question their assumptions. San Francisco, CA: Jossey-Bass.

Cavalieri, J. (2009). Veterinary student responses to learning activities that enhance confidence and ability in pig handling. Journal of Veterinary Medical Education, 36(1), 39-49. doi:10.3138/jvme.36.1.39

Clouder, L. (2005). Caring as a 'threshold concept': Transforming students in higher education into health(care) professionals. Teaching in Higher Education, 10(4), 505-517. doi:10.1080/13562510500239141

College of Veterinary Medicine. (2015). Summer research internship program for first- and second-year veterinary medicine students. Raleigh, NC: North Carolina State University. Retrieved from https://cvm.ncsu.edu/research/student-research-opportunities/ 
Dale, V., Pierce, S., \& May, S. (2010). The role of undergraduate research experiences in producing veterinary scientists. Journal of Veterinary Medical Education, 37(2), 198206. doi:10.3138/jvme.37.2.198

Entwistle, N. (2008). Threshold concepts and transformative ways of thinking within research into higher education. In R. Land, J. H. F. Meyer, \& J. Smith (Eds.), Threshold concepts within the disciplines (pp. 21-35). Rotterdam, Netherlands: Sense Publishers.

Evgeniou, E., Tsironi, M., \& Riley, D. (2015). Improving fellowship training in microsurgery: A threshold concepts perspective on the curricula of fellowship programs. Journal of Reconstructive Microsurgery, 31(8), 579-589. doi:10.1055/s-0035-1558461

Hofer, A. R., Townsend, L., \& Brunetti, K. (2012). Troublesome concepts and information literacy: Investigating threshold concepts for IL instruction. Portal: Libraries and the Academy, 12(4), 387-405. doi:10.1353/pla.2012.0039

Hofer, B. K. (2002). Personal epistemology as a psychological and educational construct: An introduction. In B. K. Hofer \& P. R. Pintrich (Eds.), Personal epistemology: The psychology of beliefs about knowledge and knowing (pp. 3-14). Mahwah, NJ: Lawrence Erlbaum Associates.

Hoggan, C. D. (2016). Transformative learning as a metatheory: Definition, criteria, and typology. Adult Education Quarterly, 66(1), 57-75. doi:10.1177/0741713615611216

Houghton, C. E. (2014). 'Newcomer adaptation': A lens through which to understand how nursing students fit in with the real world of practice. Journal of Clinical Nursing, 23(1516), 2367-2375. doi:10.1111/jocn.12451

Houtman, E. (2015, March 16). Teaching with big ideas: How a late addition to the ACRL framework might make us rethink threshold concepts. ACRLog. Retrieved from http:// 
acrlog.org/2015/03/16/teaching-with-big-ideas-how-a-late-addition-to-the-acrl-frame work-might-make-us-rethink-threshold-concepts/

Kiley, M., \& Wisker, G. (2010). Learning to be a researcher: The concepts and crossings. In J. H. F. Meyer, R. Land, \& C. Baillie (Eds.), Threshold concepts and transformational learning (pp. 399-414). Rotterdam, Netherlands: Sense Publishers.

Klipfel, K. M. (2014, November 3). This I overheard ... Threshold concepts getting laughed out of the room. [Blog post.] Rule Number One: A Library Blog. Retrieved from http:// rulenumberoneblog.com/2014/11/03/this-i-overheard-threshold-concepts-gettinglaughedout-of-the-room/

Knapp, M., \& Brower, S. (2014). The ACRL framework for information literacy in higher education: Implications for health sciences librarianship. Medical Reference Services Quarterly, 33(4), 460-468. doi:10.1080/02763869.2014.957098

Loertscher, J., Green, D., Lewis, J. E., Lin, S., \& Minderhout, V. (2014). Identification of threshold concepts for biochemistry. CBE Life Sciences Education, 13(3), 516-528. doi:10.1187/cbe.14-04-0066

Matthews, B. (2011, August 3). What can you do to help with troublesome knowledge? Librarians and threshold concepts. [Blog post.] The Ubiquitous Librarian, Chronicle of Higher Education Blog Network. Retrieved from http://chronicle.com/blognetwork/theubi quitouslibrarian/2011/08/03/what-can-you-doto-help-with-troublesome-knowledge-librar ians-and-threshold-concepts/

Meyer, J., \& Land, R. (2003). Threshold concepts and troublesome knowledge: Linkages to ways of thinking and practising within the disciplines. Edinburgh, UK: School of 
Education, University of Edinburgh. Retrieved from http://www.etl.tla.ed.ac.uk/docs/ETLreport4.pdf

Meyer, J., Land, R., \& Baillie, C. (Eds.). (2010). Threshold concepts and transformational learning. Rotterdam, Netherlands: Sense Publishers.

Mezirow, J. (2000). Learning to think like an adult: core concepts of transformation theory. In J. Mezirow \& Associates (Eds.), Learning as transformation: critical perspectives on a theory in progress (pp. 3-34). San Francisco, CA: Jossey-Bass.

Moore, J. L. (2012). Designing for transfer: A threshold concept. Journal of Faculty Development, 26(3), 19-24.

Noland, C. M., \& Rickles, N. M. (2009). Reflection and analysis of how pharmacy students learn to communicate about medication errors. Health Communication, 24(4), 351-360. doi:10.1080/10410230902889399

Perkins, D. (2008). Beyond understanding. In R. Land, J. H. F. Meyer, \& J. Smith (Eds.), Threshold concepts within the disciplines (pp. 3-19). Rotterdam, Netherlands: Sense Publishers.

Perry, W. G. (1970). Forms of intellectual and ethical development in the college years: A scheme. New York, NY: Holt, Rinehart and Winston.

Price, S. L. (2009). Becoming a nurse: a meta-study of early professional socialization and career choice in nursing. Journal of Advanced Nursing, 65(1), 11-19. doi:10.1111/j.13652648.2008.04839.x

Ryan, M. T., \& Sweeney, T. (2007). Integrating molecular biology into the veterinary curriculum. Journal of Veterinary Medical Education, 34(5), 658-673. doi:10.3138/jvme.34.5.658 
Tucker, V. M., Weedman, J., Bruce, C. S., \& Edwards, S. L. (2014). Learning portals: Analyzing threshold concept theory for LIS education. Journal of Education for Library and Information Science, 55(2), 150-165.

Vaughan, K. T., Hayes, B. E., Lerner, R. C., McElfresh, K. R., Pavlech, L., Romito, D. . . . Morris, E. N. (2013). Development of the research lifecycle model for library services. Journal of the Medical Library Association: JMLA, 101(4), 310-314. doi:10.3163/15365050.101.4.013 [begin page 130]

\section{Appendix}

\section{Key terms and definitions}

Threshold concepts: Key understandings, ways of thinking, and subjectivities that newcomers need to learn in order to participate successfully in a given field of study or practice. (Meyer et al., 2010)

Information literacy: A set of abilities requiring individuals to recognize when they need information and locate, evaluate, and use effectively the needed information. (ACRL) Epistemology: A person's beliefs about knowledge: what it is, how it is constructed, how it is evaluated, where it resides, and how it occurs. (Hofer, 2002)

Ontology: The way a person exists in the world, including "the deeply established mental and emotional inclinations that affect the overall quality and tone of one’s existence.” (Hoggan, 2016)

Transformative learning: The process by which "we transform our taken-for-granted frames of reference (meaning perspectives, habits of mind, mind-sets) to make them more inclusive, discriminating, open, emotionally capable of change, and reflective so that they may generate beliefs and opinions that will prove more true or justified to guide action. . . (Its) focus is on how 
we learn to negotiate and act on our own purposes, values, feelings, and meanings rather than those we have uncritically assimilated from others—-to gain greater control over our lives as socially responsible, clear-thinking decision makers.” (Mezirow, 2000, p. 7-8)

Research lifecycle: The process that a researcher takes to complete a project or study from its inception to its completion. (http://esciencelibrary.umassmed.edu/professional-educ/esciencethesaurus/research-lifecycle)

Meaning frame: Mental frameworks that determine how a person interprets and makes meaning from their experiences. It encompasses such things as their worldview, ways of knowing, and ways of being.

Scientific method: Principles and procedures for the systematic pursuit of knowledge involving the recognition and formulation of a problem, the collection of data through observation and experiment, and the formulation and testing of hypotheses (MerriamWebster, http://www.merriam-webster.com/dictionary/scientific\%20method) 